This is the peer-reviewed version of the following article :Pringle, J.K., 2015. Virtual geology special issue: developing training, teaching and research skillsets for geoscientists. Geology Today, 31(6), pp.213215, which has been published in final form at http://dx.doi.org/10.1111/gto.12118. This article may be used for non-commercial purposes in accordance With Wiley Terms and Conditions for self-

Introduction to the Virtual Geology Special Issue: developing training, teaching and research skillsets for geoscientists

Jamie K. Pringle

School of Physical \& Geographical Sciences, Keele University, Keele, Staffs, ST5 5BG, UK.

Email: j.k.pringle@keele.ac.uk

Current physical science students and researchers are becoming ever more diverse in their learning needs and styles, in their ways of learning and indeed their scientific backgrounds in the subjects that they study. Current schools, colleges and indeed Higher Education students are increasingly 'digital natives', digitally connected $24 / 7$ through mobile devices, generally goal-orientated and responding well to digital-based activities and tasks. Whilst the structured nature of classrooms, traditional lectures and laboratory practicals obviously still dominate geoscience teaching, and core outdoor field trips and independent mapping/research (Fig.1) are of paramount importance, more innovative complementary learning, teaching and research technologies are being developed by a wide variety of computer software developers, practitioners and educationalists. 


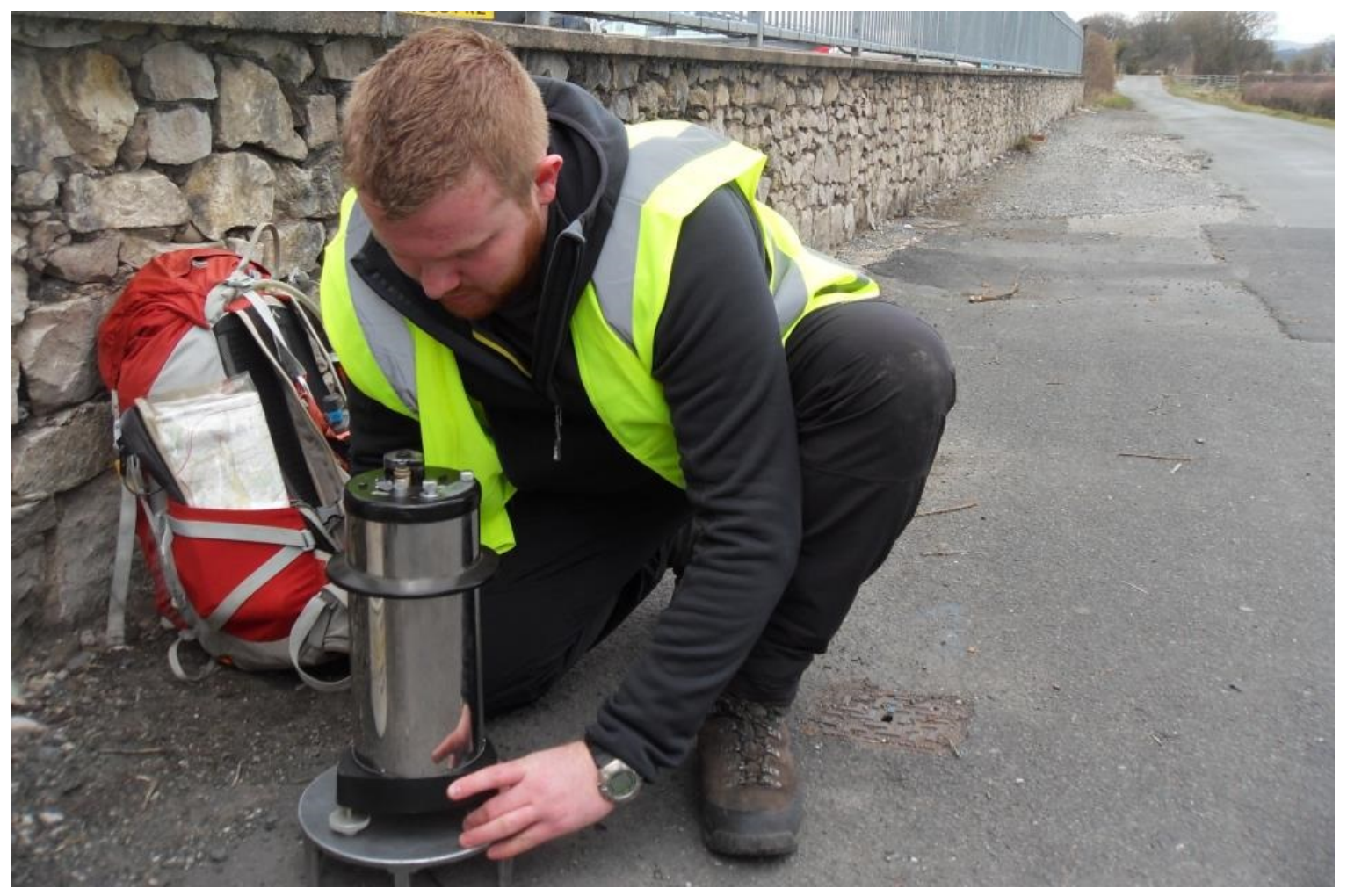

Fig. 1. Masters level Keele University student collecting gravity data on a student group-led, problem-solving residential exercise in northern England, UK.

These learning, teaching and research technologies are varied, ever changing and multi-platform. They focus on nearly all aspects of geosciences, from the small scale, for example, the Open Universities impressive virtual microscope (see http://www.virtualmicroscope.org/), which allows users to virtually investigate thin sections of rocks at varied scales and at any time or indeed physical location, the field scale, for example, the generation of virtual outcrops (Fig. 2) that can be viewed, interrogated and visualised at varies scales, to the large-scale, for example, digital geological maps at the users location that can be viewed on portable devices (see http://www.bgs.ac.uk/igeology/) and the analysis of remote sensing datasets (Fig. 3). 


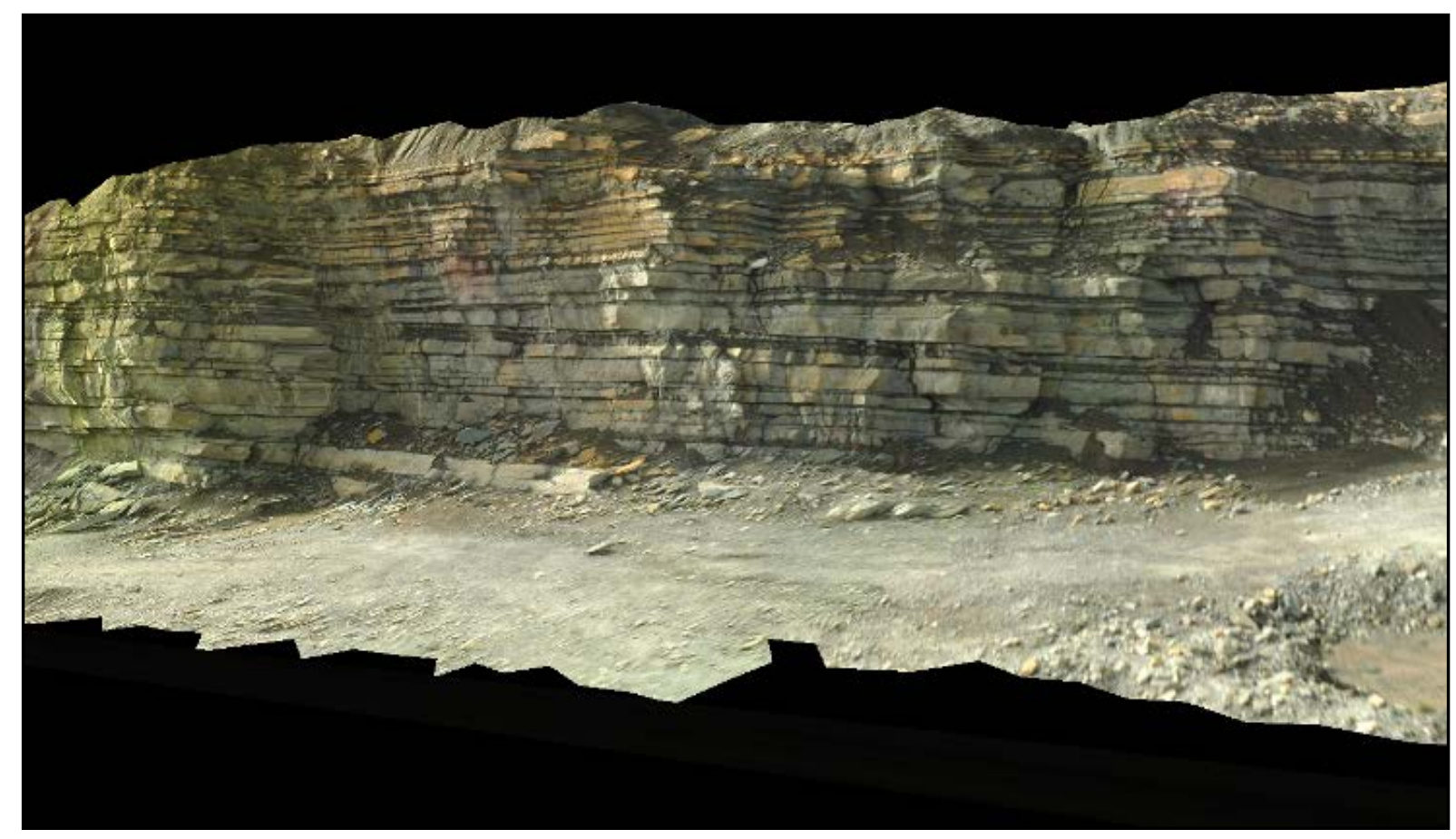

Fig. 2. Example of a virtual sedimentary outcrop in the Ainsa basin, Northern Spain.

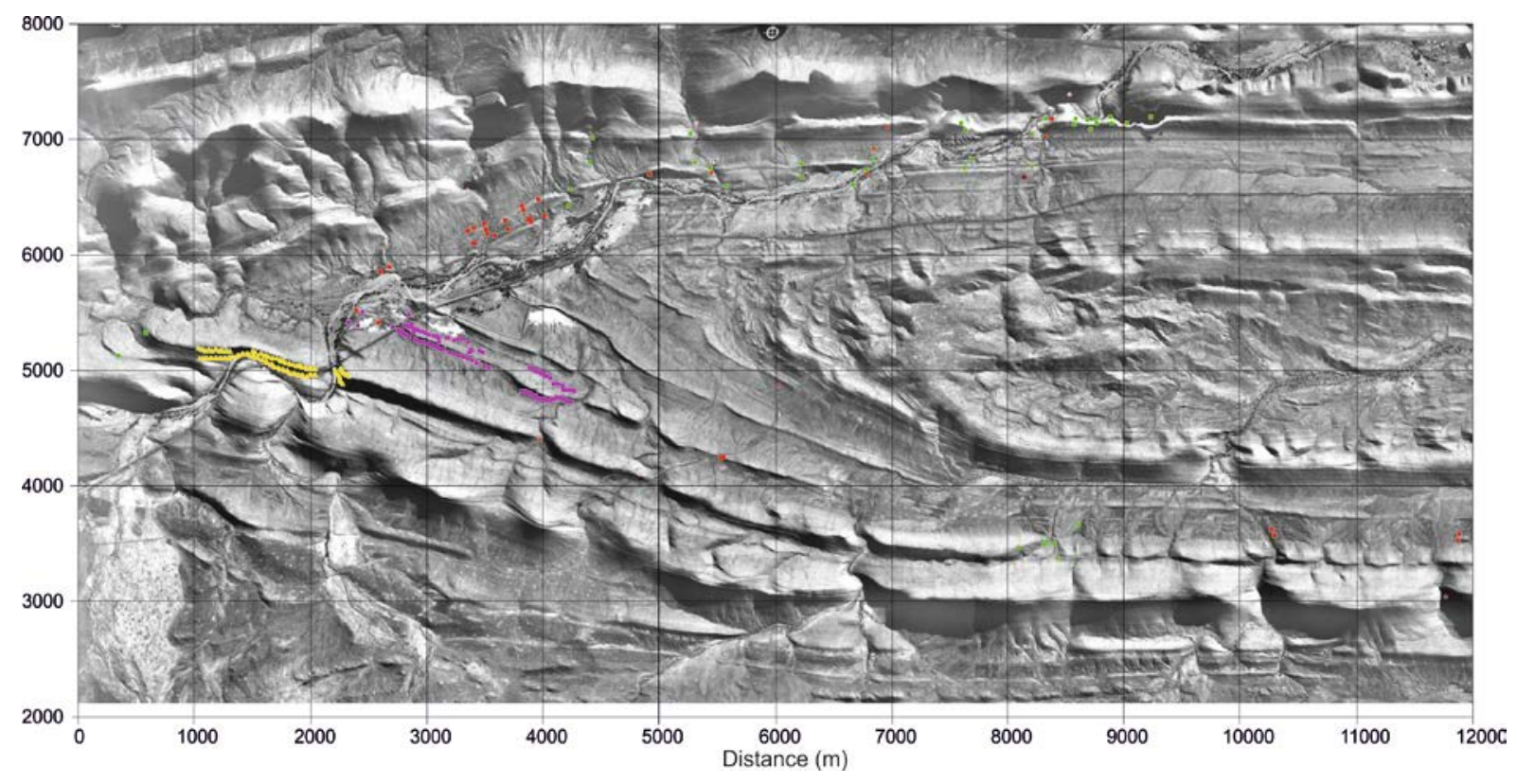

Fig. 3. Example of a remote sensing dataset, combining satellite photographs and sedimentary log positions of a syncline in the Karoo, South Africa. 
Virtual reality is also increasingly being used to help learners develop, practise and hone field and laboratory skills, for example, my GT article last year presented the benefits of educational egaming, with an increasing number of virtual case studies freely available to allow users to undertake virtual desk studies of field sites, then freely explore them, perhaps collect virtual datasets (Fig. 4) and develop resources, pinpoint virtual burial sites or mineshaft locations, etc., the applications are limitless!

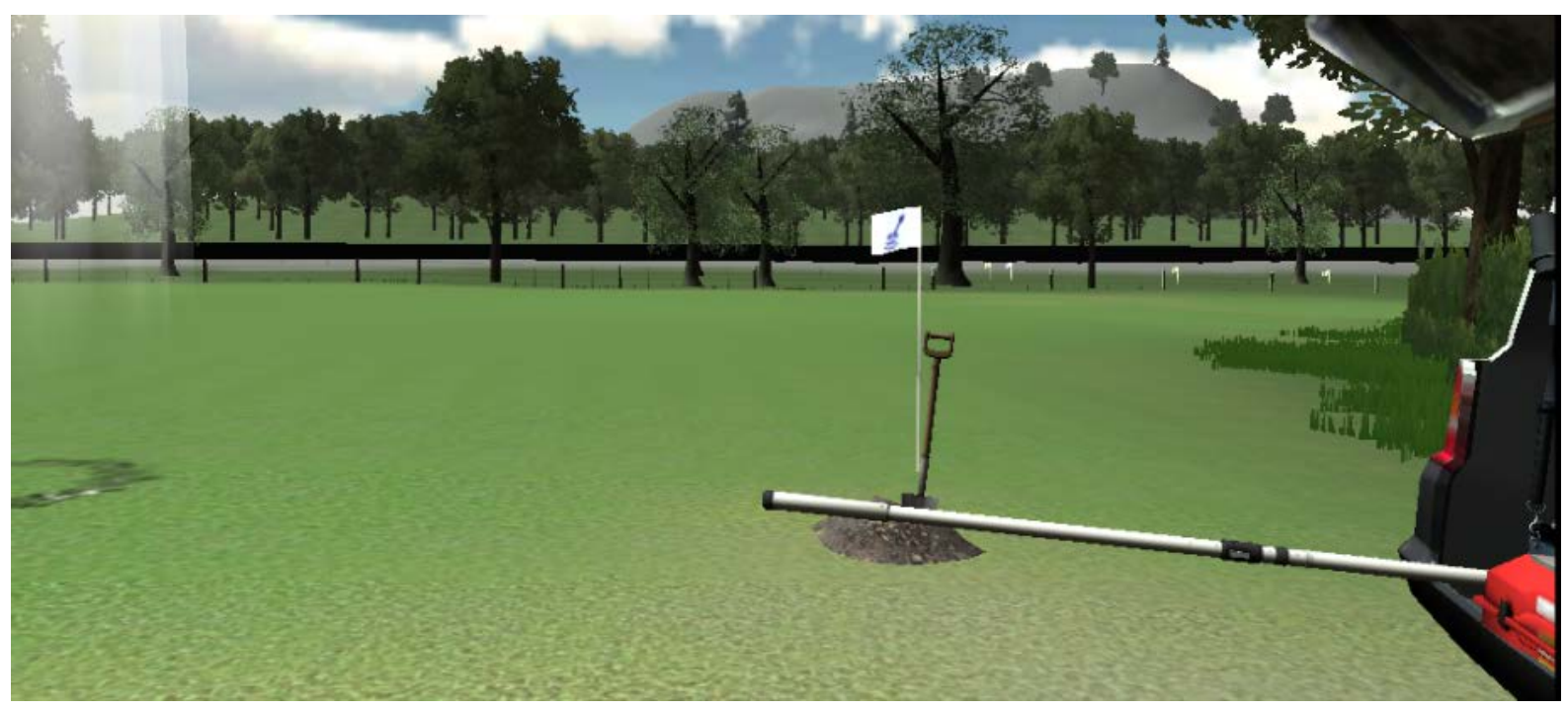

Fig. 4. Digital screenshot taken from an educational geoscience e-game developed by the author in Unity software. Initial site reconnaissance areas of interest have been flagged with the user now virtually collecting field conductivity datasets.

This special issue of Geology Today came about due to a special one day workshop on the subject of virtual learning at the Sharing Educational Practice in the Geosciences Annual Meeting of the Higher Education Network of the Geological Society of London (http://www.geolsoc.org.uk/hen/), held at Plymouth University, UK in January 2015. The special issue draws together five articles (one online) from remote sensing possibilities presented by Google Earth, through to virtual field trips, virtually 
developing mapping skills to the benefit of digital mapping in the field which are now briefly summarised.

In a timely update from Richard Lisle's 2006 GT article, Anne Mather's GoogleEarth ${ }^{T M}$ (GE) article shows how users can use it for a whole host of teaching and research applications. Now that the GE Pro version is freely available, users can use inbuilt measuring tools on current GE global surface data, use historic GE data to evaluate relative changes, import or indeed export your own data from various sources and print and save GE images at mappable resolutions. Various global examples are shown, with thoughts on GE's ability to plan fieldwork as well as the potential for virtual fieldwork and training. Anne also provides very useful data tables on keyboard shortcuts, website links of available global GE datasets and the advantages and disadvantages of using it, including the potential limitations and metadata errors to be aware of.

Tom Argles and co-authors show the benefits of a new breed of Virtual Field Trips in their article which exploits commercial (Unity) egaming software to create immersive, interactive, multi-user 3D virtual environments. Using real data at various scales (landscapes, outcrop 3D model scans and hand specimens with links to the Open University virtual microscope), it allows a rich immersive environment to be explored as if the user was on a guided field trip. They discuss its usefulness to introduce, practise and develop field observational skills, including sketching, notebook keeping and field orientation. They also explain the benefits for learners, for example, to enable those who may not otherwise be able to join due to physical issues, to avoid inclement weather, for pre-field trip familiarisation purposes and for isolated remote learners or classroom students to learn collaboratively. Finally, the virtual field trip empowers users to do things that are impossible on 
(most) physical field courses: flying, teleporting, switching scales and perspectives at will, as well as erasing other people who get in the way - at least digitally!

Jacqui Houghton and co-authors present their Virtual World Project as an article, taking the reader through how to use a virtual mapping environment as a geological mapping training tool, visiting virtual rock outcrops, reading virtual notebooks and recorded measurements and using the virtual GPS and compass to create a physical field map slip. This is a free-form experience and users can go wherever they wish; there is no proscribed route such as Tom's Virtual Field Trip describes. Subareas can also be selected if there are time constraints, the western area has relatively simple geology whilst the eastern side is more complicated. The article also described the importance of realism and the need for details that provide a sense of scale and context, including visual and audio! It also described the difficulties transferring real mapping areas to a virtual landscape, perspective, dip changes etc. Lastly results of initial pilot tryouts on HE students were also given with future plans suggested. Annabeth Robinson and co-authors accompanying on-line article explains the technicalities about how the Virtual World Project egame was developed from a physical map through $\operatorname{ArcGIS}^{\mathrm{TM}}$ to the Unity ${ }^{\mathrm{TM}}$ online immersive environment for others interested in replicating this impressive effort.

Finally Roddy Muir's Digital Field Mapping article describes the use of smartphones in the field to digitally map rather than using traditional hard copy maps, notebooks and compass clinometers. Current smartphones built-in technologies include Google ${ }^{\mathrm{TM}}$ maps or your own pre-loaded basemap to geolocate yourself in the field, pre-loading geology rock types to confirm outcrop positions, digitally recording field notes and geolocating photographs and digitally recording dip, strike and lineation orientations. I have also independently tested the accuracy of field measurements using a 
smartphone during an undergraduate field mapping course last year, and found outcrop locations, bedding and structural measurements were more accurate recorded on my smartphone when compared to my more traditional triangulation and compass measurements. Using Roddy's digital application, stereonets can also be generated and field data exported straight into Google ${ }^{\mathrm{TM}}$ maps or 3D model building packages for 3D visualisation purposes. There is finally discussion about smartphone battery limitations and some novel battery charging possibilities that could be undertaken in the field. Certainly food for thought for field-based training and research mappers.

This Special Issue and articles will, we hope, prove both informative to the reader and showcase what is currently possible, available to use now and what the potential future for both geology and the wider geosciences may hold. If we do not continue to innovate and take advantage of current technologies then we are automatically going backwards and will be rapidly left behind!

\section{Suggestions for further reading}

Cassidy, N.J. \& Pringle, J.K. 2010. What do students do? Training, research and learning: developing skills for the next generation of near-surface geophysicists. Near Surface Geophysics, v.8, pp. 445450. doi:10.3997/1873-0604.2010060

Lisle, R.J. 2006. Google Earth: a new geological resource. Geology Today, v.22, pp. 29-32. DOI: 10.1111/j.1365-2451.2006.00546.x 
Pringle, J.K. 2014. Educational egaming: the future for geoscience virtual learners? Geology Today, v.30, pp. 145-148. DOI: 10.1111/gto.12058

Pringle, J.K., Gardiner, A.R. \& Westerman, A.R. 2004. Virtual geological outcrops - fieldwork and analysis made less exhaustive? Geology Today, v.20, pp. 67-71. DOI: 10.1111/j.1365-

2451.2004.00450.x 